\title{
Comparison of optical and magnetic particle detection systems for detection of pitting damage in low speed hydraulic motors
}

\author{
E. Sjödin, P-O. Westin \\ Institute of Applied Hydraulics, Örnsköldsvik, Sweden \\ E-mail: Per-Oskar.Westin@ith.se
}

\begin{abstract}
In this study two systems for detection of pitting damage in low speed hydraulic motors were compared. These systems were based on an optical particle detector and a magnetic plug respectively. The purpose of the comparison was to determine the relative effectiveness of two methods for detecting pitting damage in a low speed hydraulic motor. In order to do this extensive testing was conducted in Bosch Rexroth Mellansel AB laboratory in Mellansel, Sweden. In the course of the project two post-processing algorithms were developed to enable automatic triggering of alarms based on measurement values from the optical sensor. The optical sensor showed earlier indication of damage than the magnetic plug and the algorithms produced automatic alarms, but there was also a higher false alarm rate when using the optical sensor compared to the magnetic plug.
\end{abstract}

Keywords: Condition Monitoring, Particle Counting, Failure Detection

\section{Introduction}

This project originated at Bosch Rexroth Mellansel AB with the realization that there was a need for an automated and continuous condition monitoring system capable of detecting the onset of pitting damage in their hydraulic motors. Pitting wear is typically characterized by an accelerating generation of wear particles. For a detailed review of wear and fatigue in rolling contacts, see [1]. While wear of components is in itself an issue, it becomes all the more important since the generation and distribution of wear particles in e.g. a hydraulic motor can be a root cause for catastrophic seizure brought on by trapping of particles in clearances between moving parts [2]. If pitting wear can be detected early, maintenance intervention can replace failing parts either during a previously planned stop or at the very least under conditions of controlled system shutdown. Generally speaking, it makes more economic sense to replace a failing bearing or roller than to risk sudden seizure and complete system stoppage.

The reasoning described above is essentially the strategy of Condition Based Maintenance (CBM), a branch of Preventive Maintenance (PM) strategy. Another PM strategy is Time Based Maintenance (TBM) which involves part replacement at intervals based on statistically determined lifetimes. A comparison of CBM and TBM strategies is given in [3]. One issue with TBM that arises with hydraulic drives running under high torque/low speed conditions is that statistical calculations of component lifetimes can be unreliable [4].
Monitoring oil condition as a means to evaluate system health and provide maintenance personnel with valuable information is not a new idea [5]. Typically, oil analyses are performed in laboratory on samples taken from the system on a regular basis. Using filtration and microscopy techniques, oil contaminants can be characterized and information can be extracted about the wear situation in the system [6]. The reliability of off-line analyses will depend greatly on oil sampling practices and some working environments are so unforgiving as to render oil sampling impractical for the purpose of debris monitoring, particularly if the level of contamination is low [7].

A common approach for on-line monitoring of oil debris is the use of magnetic chip detectors (MCD) or magnetic plugs [8]. MCDs are simple and cheap and are used for monitoring drive systems. The method is based on regular visual inspection of a magnetic plug in the oil drainage line [9]. Magnet based particle detectors/collectors have been used extensively to detect damage in rolling contact applications and machinery [10-12]. The magnetic particle detector (magnetic plug) used in this study was an Eaton Tedeco model 3A7690-1 magnetic chip collector. This is the magnetic plug currently in use by Bosch Rexroth Mellansel $\mathrm{AB}$ and it is designed in such a way that it can be removed for inspection while the test is running. Disadvantages of the magnetic chip detector approach are that it does not provide continuous monitoring and requires an experienced on-site analyst.

When considering methods for continuous on-line or in-line monitoring of oil debris, light blocking or inductive particle counting emerge as attractive alternatives. Dempsey et al. 
have shown the applicability of inductive particle counting on gear box systems [13-16]. They found that cumulative particle counting can be used to indicate the onset and progression of pitting damage in gears. A similar approach has been shown effective for damage detection in bearings [17]. These earlier studies all used inductive in-line sensors for particle detection. The advantage of an in-line sensor is that it effectively monitors the entire oil flow in the system. A major drawback is that these inductive sensors have a high detection threshold, limiting the method to studying particles of size $100 \mu \mathrm{m}$ and larger. In a more recent study, Craig et al. found that particle counters gave early detection of bearing wear [18]. In this case, while the on-line inductive particle counter only registered a single particle, an off-line, light-blocking particle counter showed significant increase in the 5-15 $\mu \mathrm{m}$ range. Research on lightblocking type particle counters is not widely published to the best of the authors' knowledge. When used for off-line analysis industry publications have criticized the method due to problems with repeatability and reproducibility [7][19]. A comparative test from the same publication used portable particle counters that could be attached directly to the system, eliminating the problem related to bottle sampling, transport and delays. In this case, all particle counters showed good performance with the caveat that it takes some time to reach a stable measurement. A very clean system can require flushing for several hours before stable values are reached [20]. For the study covered in this paper an on-line optical particle sensor delivering ISO 4406:1999 codes for fluid particle contamination was used in combination with signal post processing of the produced ISO trend curves. This type of sensor was chosen due to its high availability in the industry and if proven effective it could provide a simple yet cost effective transition to automated condition monitoring by introducing post processing algorithms in the data collection.

The purpose of this study was to compare two condition monitoring systems with respect to their effectiveness in detecting pitting damage in a low speed hydraulic motor. These two systems are based on an optical particle sensor and a magnetic plug respectively. The magnetic plug system is an existing solution and its performance will be used as a baseline in the comparison. In this comparison effectiveness will be considered in terms of Early detection of damage, False alarm rate and Ease of use. Using these points of comparison the optical sensor system would have to provide earlier detection (greater sensitivity) of damage, lower false alarm rate and require less operator training and experience to be considered as better than the existing magnetic plug system.

It is acknowledged that there exist a number of techniques that can monitor the wear situation in rotating machinery without involving oil analysis, notably vibration analysis and acoustic emission methods. Oil analysis as a means of condition monitoring was chosen based on the express research interest in debris particles as well as the availability of in-house expertise and equipment. Furthermore, there are many more oil analyses that could be considered, in particular for off-line sampling, notably LNF particle counting and classification, FTIR, SOAP/ICP or RULER®. It is beyond the scope of this work to comment in detail on each of them.

\section{Experimental}

All experimental testing in this study was done in the hydraulic laboratory at Bosch Rexroth Mellansel AB in Mellansel, Sweden. An on-site roller bearing test rig (described below) was used. It was deemed suitable as it was built specifically for fatigue testing of roller bearings.

\subsubsection{Roller bearing test rig}

The basis for the roller bearing test rig (Figure 2) used in this project is a modified Hägglunds Viking hydraulic motor (A). The Viking motor is an internal radial piston motor with stationary center (cylinder block) and rotating case (housing). This means the pistons are arranged radially and when the cylinders are pressurized the pistons apply force radially outwards against the inside of a cam ring. The piston assemblies in the Viking motor consist of a piston with integral piston rod and attached cross pin. On the cross pin there are roller bearings that during operation press against, and rotate with, the cam ring. There are also guide bearings that via slots in a guide plate keep the piston assembly in line with the cylinder, for a schematic illustration see Figure 1. These roller bearings use the cross pin as inner race. For more in-depth information on the Viking motor please refer to www.boschrextroth.se and the Viking product manual.

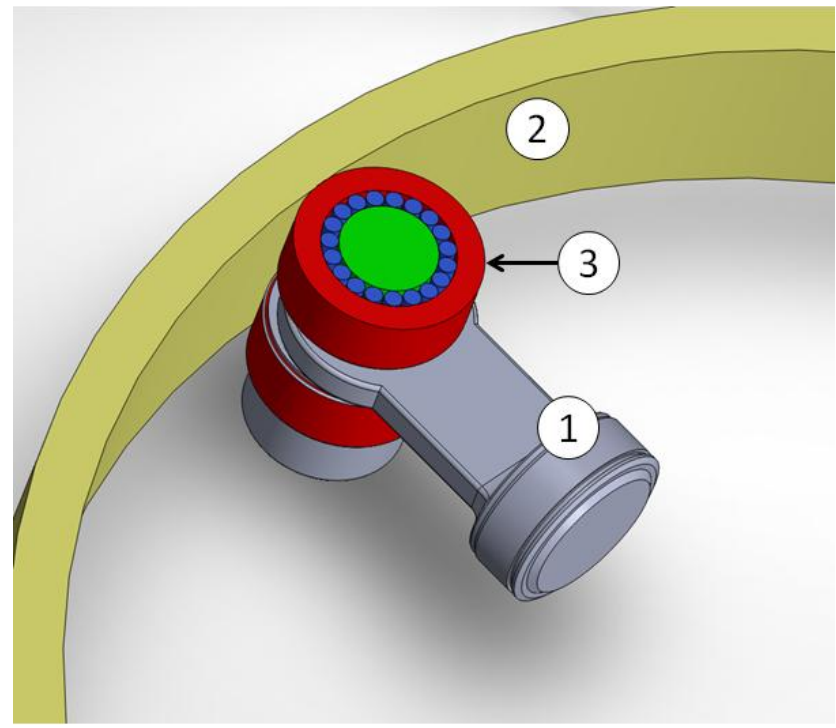

Figure 1: Cross section drawing of piston assembly in test rig where 1: piston 2: rotating cam ring with cylindrical inner surface. 3: roller bearing with outer ring (red), roller (blue) and cross pin (green). 


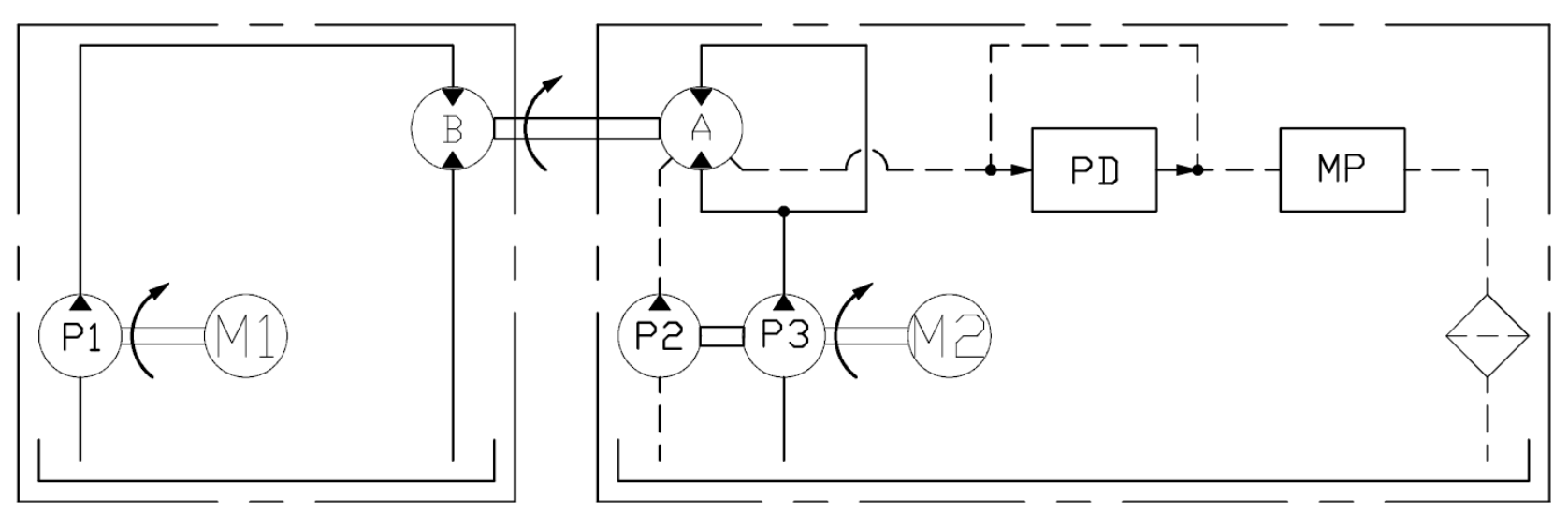

Figure 2: Schematic drawing of the test setup. The modified Viking Motor (A) is pressurized by a pump (P3). In parallel, another pump (P2) provides the flushing flow to the Viking Motor. An optical particle detector (PD) and a magnetic plug (MP) are fitted on the drain line. A separate system (M1,P1 and B) applies the rotational motion.

The modification of the Viking motor consists of the cam ring having a circular inner surface instead of the normal "wavy" profile. This modification causes the pistons to be stationary in their respective cylinders during rotation of the housing. With this modification pressurizing the cylinders and rotating the housing causes the piston roller bearings to be loaded and rotated. This rotation is provided by a second hydraulic motor (B) attached axially to the housing of the modified Viking motor.

The Viking motor and additional drive motor is mounted to a stand as to allow rotation of the housing and to keep the cylinder block stationary. Additionally there are two sets of electric motors (M1-2) and pumps (P1-3) to drive the rotation, pressurize cylinders and provide flushing flow through the housing of the Viking motor. Both in- and outflow ports on the Viking motor are pressurized during testing, this in combination with the circular cam ring results in zero flow in the pressure line due to rotation of the housing. There will however be leakage flow from the cylinders out into the housing. Through the housing there is a flushing flow which is introduced and drained from the housing via the stationary center. Thus both cylinder leakage flow and flushing flow (all flow going into the motor) leaves the motor via the housing drain line, and any particles leaving the housing will do so via the drain line flow. Therefore the drain line is the main measurement point. All

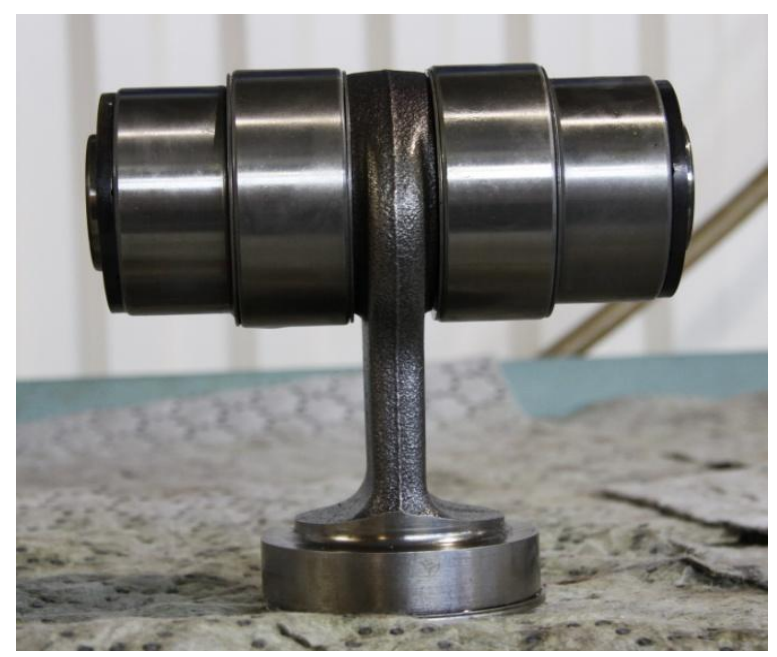

Figure 3: Actual piston assembly consisting of piston, cross pin and bearings. tests were run under equal conditions. The running parameters are found in Table 1 below.

The maximum allowed particle contamination (ISO 4406) level at startup was $16 / 13$, measured in the housing drain line. The rig was run without pressurizing the cylinders until this level was achieved before starting the test with load on the bearings.

Table 1: Operating conditions

\begin{tabular}{l|ll} 
Metric & Value & Tolerance \\
\hline $\begin{array}{l}\text { Cylinder pressure } \\
\text { Flushing oil } \\
\text { temperature }\end{array}$ & $50^{\circ} \mathrm{C}$ & +-2 \\
Housing rotation & $20 \mathrm{RPM}$ & +-1 \\
\end{tabular}

\subsubsection{Measurement equipment}

For data recording a Hydac CMU1000 was used. To it an array of sensors were connected, these are accounted for in Table 2 below.

Data from all sensors were collected every 5 minutes and saved as a .txt file. This file was then downloaded from the CMU1000 and exported to Microsoft Excel for evaluation and post processing. The sampling interval was chosen based on the duration of earlier test in the rig and the maximum number of data points in a $2 \mathrm{D}$ data series in Excel, based on these considerations a 5 minute interval was chosen to achieve adequate resolution without the amount of data causing problems with post processing.

The magnetic plug was checked daily. The checks followed the routine normally used at Bosch Rexroth Mellansel hydraulic laboratory and consisted of removing the plug and inspecting it visually for debris and then wiping it clean before reinstallation. The plug used was designed to allow removal without stopping the test. The interpretation of the magnetic plug was complicated by the presence of wear debris even under normal operating conditions. The ability to distinguish normal wear particles from particles caused 
by the onset of pitting damage is based on practical experience on the part of the operator.

The CS1000 is an on-line, light blockage type sensor; it works by leading a small $(30-300 \mathrm{ml} / \mathrm{min})$ portion of the system flow between a light source and a light sensor and detecting the shadows cast by the particles in the fluid. From the detected shadows ISO contamination levels and flow through the sensor is calculated. The lowest contamination level that the CS1000 can measure is ISO 9/8/7, below that there is simply too few particles to make an accurate measurement.

Table 2: Metrics and associated measurement equipment

\begin{tabular}{|c|c|c|c|}
\hline Metric & Equipment & $\begin{array}{l}\text { Signal } \\
\text { type }\end{array}$ & $\begin{array}{l}\text { Measurement } \\
\text { point }\end{array}$ \\
\hline $\begin{array}{l}\text { Particle } \\
\text { contamination }\end{array}$ & $\begin{array}{l}\text { Hydac } \\
\text { MCS1000 } \\
\text { and } \\
\text { CS1000 }\end{array}$ & $\begin{array}{l}\text { HSI } \\
\text { (Hydac } \\
\text { Smart } \\
\text { Interface) }\end{array}$ & Drain line \\
\hline Oil condition & $\begin{array}{l}\text { Hydac lab } \\
\text { sensor } \\
\text { HLB1300 }\end{array}$ & HSI & Drain line \\
\hline Temperature & $\begin{array}{l}\text { JUMO } \\
100{ }^{\circ} \mathrm{C}\end{array}$ & $\begin{array}{l}4 \ldots 20 \\
\mathrm{~mA}\end{array}$ & $\begin{array}{l}\text { Pressure, } \\
\text { flushing and } \\
\text { drain line }\end{array}$ \\
\hline Pressure & $\begin{array}{l}\text { Hydac } \\
\text { HDA } 4745 \\
0-16 \text { and } 0- \\
400 \text { bar }\end{array}$ & $\begin{array}{l}4 \ldots .20 \\
\mathrm{~mA}\end{array}$ & $\begin{array}{l}\text { Pressure, } \\
\text { flushing and } \\
\text { drain line }\end{array}$ \\
\hline Flow & $\begin{array}{l}\text { VSE vs } 0,2 \\
\text { EP012V } \\
5000 \\
\text { pulses/liter }\end{array}$ & $\begin{array}{ll}0-5 & \mathrm{~V} \\
\text { pulse } & \end{array}$ & Flushing line \\
\hline RPM & $\begin{array}{l}\text { Lenord } \\
\text { Bauer, } \\
2500 \\
\text { pulses/rev. }\end{array}$ & $\begin{array}{ll}0-5 & \mathrm{~V} \\
\text { pulse } & \end{array}$ & Motor housing \\
\hline Magnetic plug & $\begin{array}{l}\text { Tedeco } \\
\text { 3A7690-1 }\end{array}$ & $\begin{array}{l}\mathrm{n} / \mathrm{a}, \\
\text { ocular } \\
\text { inspection }\end{array}$ & $\begin{array}{l}\text { Drain line } \\
\text { (downstream } \\
\text { of other } \\
\text { sensors) }\end{array}$ \\
\hline
\end{tabular}

\section{Results}

Tests were run for a total of 4301 hours, in this time the test was stopped 6 times and produced 7 instances of identified pitting damage. The time from start of test to failure of the individual piston assemblies ranged from $839 \mathrm{~h}$ to $3166 \mathrm{~h}$, with median and mean time being $1808 \mathrm{~h}$ and $1770 \mathrm{~h}$ respectively. At the end of testing two piston assemblies remained from the original set of eight present in the rig at the start of testing, the others having suffered damage and been replaced. This wide range exemplifies the complexity in calculating expected component lifetime.

\subsubsection{Measurement data}

Measurement data was imported to Microsoft Excel where it was analyzed and compiled into trend curves after each stop in testing. Studying these trend curves it was clear that the only measurement values that showed changes correlating to pitting damage was the ISO levels reported by the CS1000, and under certain circumstances the flow value measured by the CS1000. A typical trend curve showing the ISO levels is shown in Figure 4 where a complete test cycle from filtering and startup through steady state operation to stopping the test due to damage is shown.

At the start of the test, after filtering, there is a large spike in the ISO levels before settling at steady state operation. Similar spikes were generated when the test was stopped and restarted again. Such spikes in ISO values correlating with surges in flow has been observed by [21] and [22] when using optical particle counting in fluids. Detecting the transition between steady state operation and phase of increasing ISO levels due to damage is complicated both by these spikes and by the noise in the signal. Automation of the detection is desirable since it makes damage detection independent of operator judgment. To achieve this, post processing algorithms were developed in order to obtain a more easily interpreted trend curve and to trigger alarms based on that curve. As the algorithms for detecting damage were intended for use in the CMU1000 in real time during testing they had to be kept as simple as possible. Therefore more advanced methods such as fuzzy logic or neural nets were not used. The algorithms that were developed are described in the section below.

\subsubsection{Data post processing}

In order to achieve automatic triggering of alarms based on the ISO levels measured by the CS1000 two post processing algorithms were developed, the first for converting the ISO levels trend curve into a more easily interpreted form, the second algorithm then uses the shape of this new trend curve to trigger alarms.

The first algorithm is based on the steady state ISO values found during testing and the cumulative time these steady state values are exceeded. At each sampling interval the algorithm is evaluated and the cumulative sum $\mathbf{C}$ taken according to the conditions in the algorithm. Applying this algorithm to the data series showed in Figure 4 and trending the $\mathbf{C}$ value produces the blue curve showed in Figure 5 (the green alarm curve is described below).

This curve has less noise than the ISO curves and a characteristic behavior when damage occurs. The absolute value of $\mathbf{C}$ is not of particular interest, as it can vary widely as a result of spikes in the ISO values caused by for example stopping and restarting the test, instead the shape of the curve is used for indication of damage. The characteristic behavior of the curve when damage occurs is an accelerating increase that starts off slowly, as opposed to an increase caused by a spike in the ISO levels which produces a decelerating increase that starts out very steep. In order to detect this accelerating increase a second algorithm was developed. It works by comparing the increase in $\mathbf{C}$ over consecutive periods of time to determine if the value is accelerating. The length and number of these consecutive 
periods of time were found iteratively by applying the algorithms to measurement data in post processing.

A warning variable was introduced, which was set to 1 if accelerated cumulative wear was detected and 0 if otherwise. This variable was then plotted together with the $\mathbf{C}$ trend curve and thus produced the green alarm curve in Figure 5. As can be seen in the figure the alarm triggers when the curve starts accelerating upwards from its slow steady state increase, but does not trigger as a result of the spike in ISO values at the start of the test. However there were some false alarms during filtering. The performance of this alarm as compared to the magnetic plug will be discussed under method comparison below.

\subsubsection{Method comparison}

The purpose of this study was to compare the effectiveness of a light blockage type particle sensor with an existing magnetic plug particle detector. Effectiveness was considered in terms of early detection, false alarm rate, and ease of use.

Early detection: on all but one occasion of pitting damage the CS1000 responded before the magnetic plug, that is; increasing levels of particles were detected before the test was stopped.

False alarm rate: during all of the testing done in this study the magnetic plug system produced only one false alarm, as opposed to the CS1000 and post processing that produced numerous false alarms.

Ease of use: the magnetic plug requires experienced operators that are able to interpret the growth in the amount of debris on the magnet; this will also cause interpretations to vary with different operators. The output from the post processing of ISO levels is digital, damage or no damage, and thus is not dependent on the experience or judgment of the operator.

In summary the CS1000 with post processing is capable of earlier detection and is easier to use, but is also affected by significantly higher false alarm rates when compared to the magnetic plug being used by experienced operators.

\section{Discussion}

Earlier studies [13-16] have used cumulative particle counting with inductive particle sensors in combination with fuzzy logic post processing to detect pitting damage in gears. Results indicated that cumulative mass was a good predictor of pitting damage, and that fuzzy logic was a good technique for setting alarm thresholds. A similar approach to damage detection was used in this study.

During initial testing it became clear that the only measurement value which showed changes corresponding to pitting damage occurring was the ISO class and flow values measured by the CS1000 particle counter. An effort was therefore made to have the system automatically trigger alarms based on the ISO class values. To achieve this, measured values had to be post processed to produce a trend curve that more clearly indicated when changes started to occur in the ISO class values. A means of automatically interpreting this new trend curve was also necessary. Two algorithms, one for post processing and one for automatic interpretation, were developed.

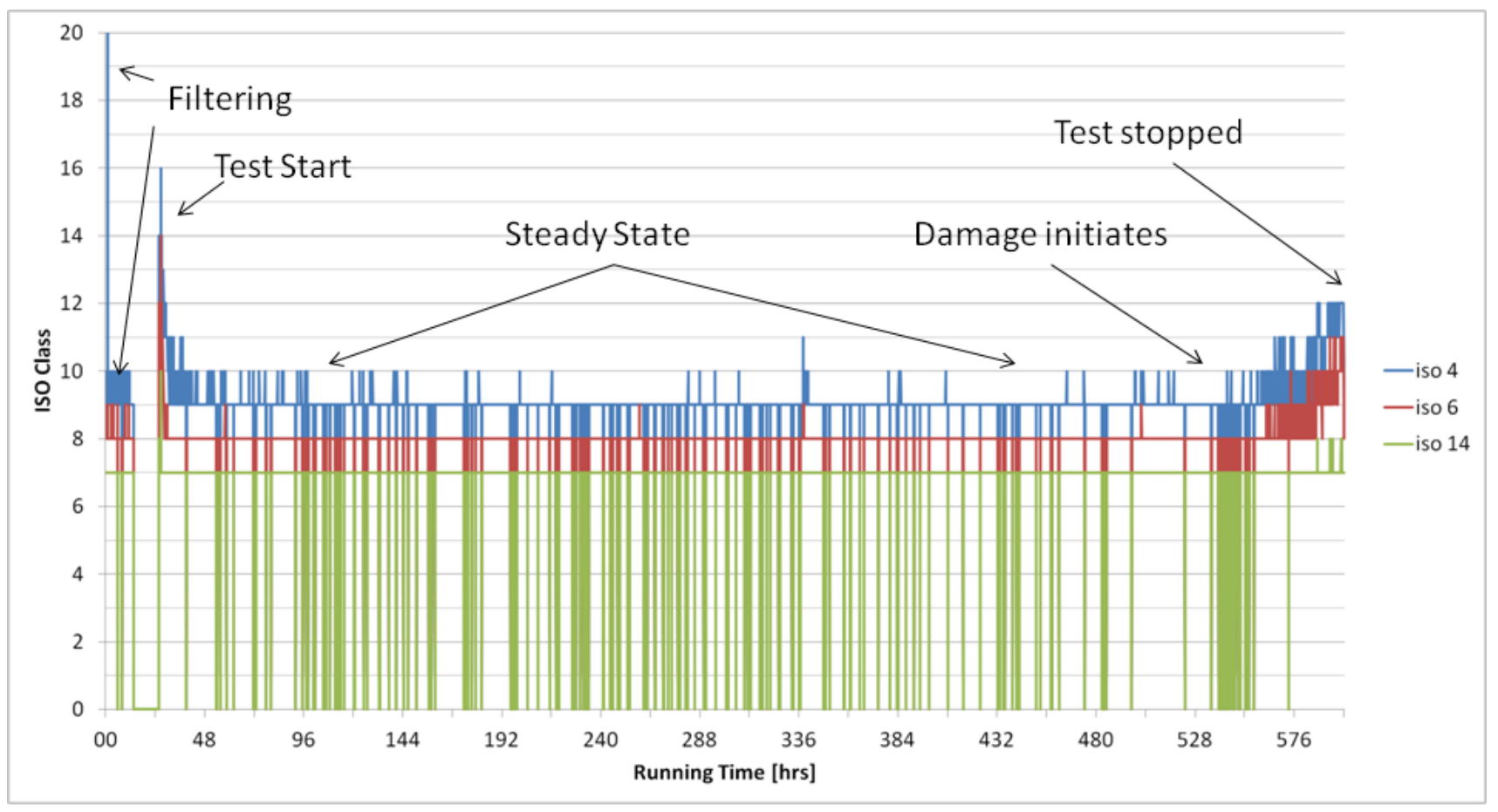

Figure 4: ISO levels trend curve by optical particle counting. 


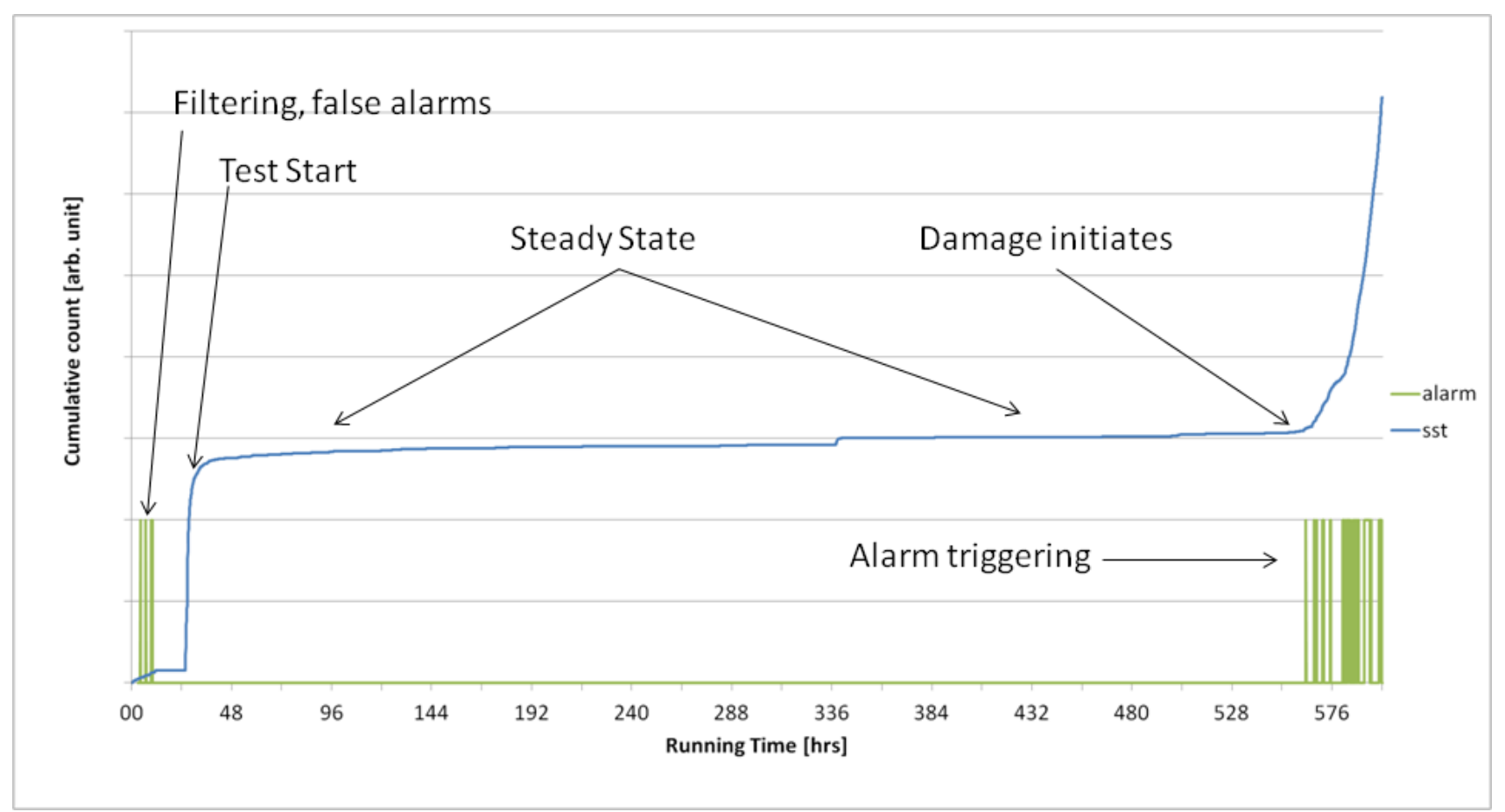

Figure 5: Cumulative counting trend curve and triggered alarms

The post processing algorithm developed in this study produces a trend curve with behavior similar to cumulative counting. But the absolute value can vary widely as a result of spikes in the ISO values caused by stopping and restarting the test. Using the absolute value to trigger alarms would therefore be problematic. Instead the algorithm for triggering of alarms uses the shape of the trend curve to detect when particle levels start to increase from a steady state value, thus avoiding the problems with widely varying absolute values by looking at differences over time instead. Both algorithms developed in this study are very simple mathematical and logical operations; this should make it possible to incorporate in most data collection systems.

It should be noted that all testing in this study was done under constant conditions such as temperature, flow, RPM, load etc. Stopping and starting the test caused large spikes in the ISO levels, and it seems likely that running the test under varying conditions would cause the ISO levels to vary accordingly. This would make damage detection more difficult, as the method presented here relies on steady state ISO values as limits for the cumulative counting. In principle, the method is valid for any hydraulic system, regardless of size or speed, provided that a) a drainage line exists which carries particle contaminants from the wear location and b) a suitable pre-processing of the signal is available which can aid in establishing steady state wear during working conditions. More testing is therefore required to investigate how varying conditions affect ISO trend curves, and how to compensate for such variation. Also, a rig made specifically for this type of testing should be built, as it is has not been investigated if the design of the piston assemblies used in this study affect the release of wear particles from the loaded components out into the oil. A means to determine remaining useful component life based on the ISO values would also be desirable.

\section{Conclusions}

Extensive testing of wear detection was performed using a light blockage type particle sensor and a magnetic plug particle detector. Methods were developed for particle sensor signal processing and automatic alarm generation. When comparing the particle sensor system to the magnetic plug system in terms of early detection, false alarm rate, and ease of use some conclusions can be drawn.

1. Early detection: the optical sensor reacts before the magnetic plug.

2. False alarm rate: with experienced operators the magnetic plug has significantly lower false alarm rate than the optical sensor and post processing algorithms.

3. Ease of use: with the post processing algorithms used the optical sensor does not require an experienced operator, and output is independent of operator experience.

The optical sensor in combination with signal post processing has shown promise as a means of automatic early detection of pitting damage, but the high false alarm rate is a major problem and more work is needed to reduce this without compromising measurement sensitivity. More work is also needed to investigate how ISO levels behave in a system with varying operating conditions.

\section{Acknowledgements}

This work was performed in close collaboration and with support from Bosch Rexroth Mellansel AB. Financial support for the project was provided by Tillväxtverket as part of EU funding for regional development. 


\section{References}

[1] J. Halme and P. Andersson, "Rolling contact fatigue and wear fundamentals for rolling bearing diagnostics - state of the art," Proceedings of the Institution of Mechanical Engineers, Part J: Journal of Engineering Tribology, no. 224, pp. 377-393, 2010.

[2] D. Nilsson, "Investigations for Enhanced Tribological Performance of a Hydraulic Motor," Doctoral Thesis, Luleå University of Technology, 2011

[3] R. Ahmad and S. Kamaruddin, "An overview of time-based and condition-based maintenance in industrial application.," Computers \& Industrial Engineering, vol. 63, no. 1, pp. 135-149, 2012.

[4] D. Nilsson and S. Berg, "Wear and life of roller bearings under low speed and clean environment, a comparison of Me-C:H coated and uncoated rollers," in Nordic Symposium on Tribology, 2002.

[5] J. A. Briggs, "Determining contamination levels in hydraulic systems," in Annual Meeting, American Society of Lubrication Engineers, 1969.

[6] F. D. Norvelle, "Contamination control - the key to reliability in fluid power systems," Wear, vol. 94, no. 1, pp. 47-70, 1984.

[7] L. Arvidsson, "Partikelräkning eller gravimetri vid föroreningsanalys av hydraulolja," Fluid Scandinavia, no. 3, 1997.

[8] C. Evans, "Wear debris analysis and condition monitoring," NDT international, no. June, pp. 132134,1978

[9] R. Sjölund and E. Söderkvist, "Tillståndskontroll av hydraulmotorer med hjälp av magnetindikator," Master's Thesis, Luleå University of Technology, Luleå, 2006.

[10] S. Dory and T. Hansen, "Magnetic plug inspection enhanses condition-based maintenance," Practicing Oil Analysis, no. September, 2003.

[11] M. H. Jones, "Particle Transfer from Magnetic Plugs," Swansea Tribology Services Ltd., University of Wales Swansea, 1998.

[12] S. Raaduni, "Magnetic Chip Detector (MCD) Wear Particle Analysis," King Mongkut's University of Technology, Bangkok, 2002.

[13] P. J. Dempsey, "Gear Damage Detection Using Oil Debris Analysis," NASA, Glenn Research Center, Cleveland, Ohio, 2001.
[14] P. J. Dempsey and A. A. Afjeh, "Integrating Oil Debris and Vibration Gear Damage Detection Technologies Using Fuzzy Logic," in International 58th Annual Forum and Technology Display, Montreal, 2002.

[15] P. J. Dempsey, G. Kreider and T. Fichter, "Investigation of Tapered Roller Bearing Damage Detection Using Oil Debris Analysis," Power transmission engineering, february 2007.

[16] D. G. Lewicki, P. J. Dempsey, G. J. Heath and P. Shanthakumaran, "Gear Fault Detection Effectiveness as Applied to Tooth Surface Pitting Fatigue Damage," National Aeronautics and Space Administration, Washington, DC, 2009.

[17] J. L. Miller and D. Kitaljevich, "In-line oil debris monitor for aircraft engine condition assessment," in IEEE Aerospace conference proceedings, 2000.

[18] M. Craig, T. J. Harvey, R. J. K. Wood, K. Masuda, M. Kawabata and H. E. G. Powrie, "Advanced condition monitoring of tapered roller bearings, Part 1," Tribology International, vol. 42, no. 11-12, pp. 1846-1856, 2009.

[19] S. Sjöberg, "Partikelräkning eller gravimetri för föroreningsbestämning av hydraulolja," Fluid Scandinavia, no. 1, 1997.

[20] B. Andersson, "Jämförande utvärdering av partikelräknare," Fluid Scandinavia, no. 5, 1996.

[21] A. Östgren, "Mätning av föroreningar i hydraulolja med automatisk partikelräknare," LTU, Luleå, 1996.

[22] B. Verdegan, A. True-Dahl, W. Haberkamp, N. Blizard, D. Genter and E. Quillen, "Filtration Solutions for High Pressure Common Rail Fuel Systems," Cummins Inc., 2008. 